\title{
P-element repressor autoregulation involves germ-line transcriptional repression and reduction of third intron splicing
}

\author{
Siobhan E. Roche, Michael Schiff, and Donald C. Rio \\ Department of Molecular and Cell Biology, University of California, Berkeley, California 94720-3204 USA
}

\begin{abstract}
P cytotype is a regulatory state, characteristic of Drosophila P-strain females, in which P-element transposition is repressed. $P$ cytotype is established maternally in the germ line but is also dependent on the presence of $P$ elements in the zygote. One aspect of $P$ cytotype involves transcriptional repression of the P-element promoter. Here, we show that transcriptional repression by $P$ cytotype in the female germ line occurs by a general promoter-independent mechanism with heterologous promoters carried in P-element vectors. P-cytotype transcriptional repression results in low levels of pre-mRNA and a reduction in splicing of the P-element third intron (IVS3)-containing mRNA, thus causing an increase in the proportion of 66-kD repressor mRNA. Increased retention of IVS3 in P cytotype would result in an autoregulatory loop of 66-kD repressor production. This combination of germ-line transcriptional repression and splicing control provides a mechanism to maintain repression during the maternal inheritance of $P$ cytotype. These findings suggest that transcriptional repression may play an additional role in the regulation of gene expression, namely allowing alteration of pre-mRNA splicing patterns.
\end{abstract}

[Key Words: Tissue specificity; germ-line transcriptional control; pre-mRNA splicing regulation; germ-line P-element transposition]

Received January 25, 1995; revised version accepted April 13, 1995.

P element transposition in Drosophila is controlled in two ways: (1) transposition is restricted to the germ line by alternative RNA splicing (tissue specificity), and (2) transposition only occurs when a P-strain male /carrying $\mathrm{P}$ elements) is mated to an $\mathrm{M}$-strain female (lacking $\mathrm{P}$ elements) but does not occur in the reciprocal cross. $\mathrm{P}$-strain females are said to possess "P cytotype," the regulatory state by which transposition is repressed. P cytotype is initially inherited maternally and in a manner similar to cytoplasmic inheritance but is ultimately determined zygotically by the presence of chromosomal P elements (for review, see Engels 1983, 1989; Rio 1991). At least part of the repressive activity of $\mathrm{P}$ cytotype is caused by repressor proteins encoded by the P elements, and this repressive activity can be influenced by genomic position (Robertson and Engels 1989; Misra and Rio 1990; Misra et al. 1993). Genetic studies of cytotype suggested that repressor synthesis would be autoregulatory in the germ line (Engels 1983; O'Hare and Rubin 1983), but the underlying mechanism has remained elusive.

Cytotype repression of P-element mobility has both maternal and zygotic components (Engels 1983, 1989). Genetic assays for cytotype have allowed the detection of two types of regulatory P elements. The complete 2.9$\mathrm{kb} \mathrm{P}$ elements encode the $66-\mathrm{kD}$ repressor protein (Misra and Rio 1990; Gloor et al. 1993), whereas the smaller internally deleted elements encode truncated repressor proteins, such as the KP protein (Black et al. 1987; Rasmusson et al. 1993). Complete $P$ elements are capable of exhibiting the repressive maternal effect of $\mathrm{P}$ cytotype, depending on their genomic position, when the repressor elements come from the mother (Misra et al. 1993). Other studies using 66-kD-encoding $\mathrm{P}$ elements indicated that in the soma repression occurs zygotically, that is, regardless of whether the repressor elements are inherited from the mother or father (Robertson and Engels 1989; Misra and Rio 1990). Genetic studies have shown that deleted $\mathrm{P}$ elements, such as $\mathrm{KP}$, are incapable of showing the strong maternal effect repression characteristic of the complete elements (Lemaitre et al. 1993; Rasmusson et al. 1993). More recent genetic studies, using a P-cytotype strain carrying two complete P elements, have demonstrated the existence of a "pre-P cytotype" state in which maternal cytoplasm can confer repressive effects for one generation in the absence of P-element DNA and that can be maternally inherited in subsequent generations if oocytes are fertilized with sperm carrying full-length P elements (Ronsseray et al. 1993). The repressive effects of $\mathbf{P}$ cytotype correlate with the ability of repressor-producing $\mathrm{P}$ elements to transcriptionally re- 
press enhancer trap P-element promoter- $\beta$-galactosidase $(\mathrm{P}-$ lacZ) fusion genes (Lemaitre and Coen 1991). However, in somatic tissues repression of $\mathrm{P}-\mathrm{lacZ}$ elements is zygotic and does not exhibit the maternal effect of $P$ cytotype (Lemaitre and Coen 1991). This zygotic repression of the $\mathrm{P}-\mathrm{lacZ}$ elements was shown to occur at the transcriptional level, but transcriptional repression alone is insufficient to account for the autoregulatory nature of repressor activity (O'Hare and Rubin 1983) More recently, assays of $\mathrm{P}-\mathrm{lacZ}$ repression in the germ line using complete repressor elements showed the maternal effect characteristic of $P$ cytotype (Lemaitre et al. 1993). The fact that the P-element third intron (IVS3) is differentially spliced in the germ line to allow both repressor and transposase synthesis and that full-length $\mathrm{P}$ elements are required for inheritance of $P$ cytotype suggested that perhaps IVS3 splicing might play a role in repressor autoregulation (Laski et al. 1986; O'Hare et al. 1992; Lemaitre et al. 1993; Ronsseray et al. 1993).

Here, we show that the autoregulatory nature of P cytotype in the germ line is brought about through a combination of transcriptional repression and alteration of P-element IVS3 splicing. We directly examine the transcriptional regulatory effects of $P$ cytotype on splicing of the P-element IVS 3 in the female germ line during oogenesis. Our findings indicate that the transcriptional regulatory effects of $P$ cytotype are not restricted to the P-element promoter, suggesting a general chromatinbased mechanism of repression. Maternal promoters were used to express $l a c Z$ reporter genes carrying the germ-line-specific P-element IVS3 in females during oogenesis. These fusion genes, carried in P-element transformation vectors, exhibited germ-line-specific expression patterns and allowed direct examination of the ratio of spliced to unspliced IVS3 mRNA in this tissue. These studies show that in the M cytotype IVS3 is incompletely spliced such that both the $87-\mathrm{kD}$ transposase and the $66-\mathrm{kD}$ repressor mRNAs would be made in the germ line. Surprisingly, P cytotype transcriptional repression causes a reduction in IVS3 splicing yeilding more unspliced P-element IVS3-containing mRNA. This increase in third intron retention would increase production of the $66-\mathrm{kD}$ repressor protein. This autoregulatory mechanism involving both transcriptional repression and IVS3 retention provides an explanation for the positive feedback of P-cytotype repression. Because transcription and splicing are thought to take place in the same nuclear compartment (Beyer and Osheim 1988; JiménezGarcía and Spector 1993; Xing and Lawrence 1993), it seems plausible that decreased levels of pre-mRNA resulting from transcriptional repression could lead to altered splicing patterns and may be an important mechanism to control or influence expression of different protein isoforms in distinct tissues.

\section{Results}

Previous studies indicated that $\mathrm{P}$ cytotype caused transcriptional repression from the P-element promoter in the germ line and soma (Lemaitre and Coen 1991; Le- maitre et al. 1993). Other genetic studies had linked P-cytotype repression to chromatin effects through the zeste-white interaction (Coen 1990). To examine the specificity of cytotype transcriptional control, we were interested in testing the ability of P cytotype to act more generally on heterologous promoters carried in P-element vectors. Another important aspect of $P$ cytotype is that in the germ line repression exhibits a maternal effect (Engels 1983, 1989; Rio 1991). Genetic studies have suggested that germ-line maternal repressor activity requires a positive feedback to maintain repression (Engels 1983; O'Hare and Rubin 1983). One possible target for repressor autoregulation is splicing of the germ-line-specific IVS3 (Laski et al. 1986; O'Hare et al. 1992; Lemaitre et al. 1993). However, because natural $P$ elements are transcribed in both the germ line and soma, previously it had not been possible to directly examine P-element transcripts that are exclusively germ line derived. Thus, we were also interested in examining the potential effects of $\mathrm{P}$ cytotype on splicing of transcripts containing the P-element IVS3 that were expressed exclusively in the female germ line as a possible means to autoregulate repressor production.

\section{P-cytotype transcriptional repression in the female germ line occurs by a promoter-independent mechanism}

To express P-element third intron-containing transcripts exclusively in the germ line, we used the hsp 83 and vasa promoters to transcribe IVS3-lacZ fusion genes during oogenesis. It is known that the $h s p 8$ and vasa promoters are active in germ-line nurse cells but not detectable in the somatic follicle cells surrounding the egg chamber (Ding et al. 1993; Hay et al. 1988; Lasko and Ashburner 1988). The hsp 83 and vasa promoters were fused to a P-element DNA fragment carrying the third intron (IVS3) and flanking exons or a DNA fragment carrying exon but no IVS3 sequences ( $\Delta 2-3)$. A fragment containing a translation start site sequence, a translation start codon (Cavener 1987), and a protein nuclear localization signal (NLS) was fused upstream of the intron/exon sequences such that it was in-frame to the Escherichia coli $\beta$-galactosidase $(l a c Z)-n e o$ fusion gene $(\beta$-geo) that was inserted downstream of IVS3 (Friedrich and Soriano 1991). The entire promoter-gene fusion was placed in a P-element transformation vector that contained the P-element termini including the P-element promoter (Fig. 1; see Materials and methods). These fusion genes were introduced into the Drosophila germ line by P-elementmediated transformation (see Materials and methods), and their chromosomal positions were determined by genetic mapping.

To examine the effects of $P$ cytotype on these maternal promoters, we first used a lac $Z$ activity assay. The lac $Z$ histochemical staining patterns of the $\mathrm{P}\left[\mathrm{ry}^{+}\right.$; hsp83-IVS3- $\beta$-geo] and $\mathrm{P}_{\left[y^{+}\right.}{ }^{+}$; vasa-IVS3- $\beta$-geo] transgenes were examined in dissected ovaries, and both the IVS3-containing and IVS3-lacking constructs expressed $\beta$-galactosidase $(1 a c Z)$ activity exclusively in the germ- 


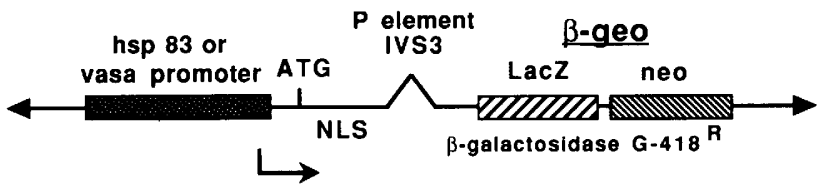

Figure 1. Schematic drawing of the maternal promoter IVS3$\beta$-geo transposons. The $h s p 83$ or vasa promoter fragments are indicated by the stippled rectangle. The P-element termini are indicated by arrows and are derived from $\mathrm{pDm} 30$ (Mismer and Rubin 1987), which contains P-element nucleotides 1-585 and 2685-2907 (Rubin and Spradling 1983). The P-element IVS3 is indicated by a pyramid, and the translation initiation site (ATG), nuclear localization signal (NLS), and transcription start site (angled arrow) are indicated. The $\beta$-geo gene is indicated by hatched rectangles.

line nurse cells and oocyte (Fig. 2A,D; data not shown for $\Delta 2-3$ construct alone). Typically, there was no detectable $l a c Z$ activity in the somatic follicle cells surrounding the egg chamber with either construct. There was a low level of lacZ staining in the somatic dorsal appendages with both the $\mathrm{P}\left[\mathrm{ry}^{+}\right.$; vasa-IVS3- $\beta-$ geo $]$ and $\mathrm{P}\left[\mathrm{ry}^{+}\right.$; vasa- $-\mathrm{2} 2-$ $3-\beta-$ geo] constructs (Fig. 2A,D). To examine the effect of $P$ cytotype on the pattern of $l a c Z$ expression, reciprocal genetic crosses were performed between the $\beta$-geo transformants and the P-cytotype-producing strain Lk-P(1A) (Ronsseray et al. 1991). This strain contains two fulllength $\mathrm{P}$ elements at the tip of the $\mathrm{X}$ chromosome. Ovaries of female progeny from these crosses were examined for lac $Z$ activity. When $\mathrm{P}\left[\mathrm{ry}^{+}\right.$; hsp83-IVS3- $\beta$-geo $\mid$ males were crossed to Lk-P(1A) females, there was a complete absence of $l a c Z$ activity in ovaries from these female progeny (Fig. 2C). This result demonstrates that $\mathrm{P}$ cytotype can repress $l a c Z$ expression from a heterologous promoter when carried within a P-element vector. This repression of $l a c Z$ expression also occurred where reporter strain males carrying $\mathrm{P}\left[\mathrm{ry}^{+}\right.$; hsp83- $\left.\Delta 2-3-\beta-g e o\right]$, which lacked IVS3, were mated to Lk-P(1A) females (Fig. 2E) but not with the reciprocal cross (Fig. 2D). Thus, repression occurred regardless of whether IVS3 was present (Fig. 2C) or absent (Fig. 2E), suggesting that transcriptional repression, not splicing of IVS3, caused the loss of $l a c Z$ staining. This transcriptional effect was confirmed by RNA in situ hybridization (Fig. 3; see below).

The repression of $l a c Z$ staining required inheritance of the $\mathrm{P}$ cytotype maternally, as no repression was observed in the reciprocal cross $\left(\mathrm{P}\left[\mathrm{ry}^{+} ;\right.\right.$hsp83-IVS3- $\beta$-geo $]$ females $\times$ Lk-P(1A) males) (Fig. 2B). We observed the same maternal repression of $l a c Z$ activity when $\mathrm{P} \mid \mathrm{ry}^{+}$; vasa-IVS3- $\beta$-geo] transformants were tested and also when both types of transformants were mated to females from the natural P-strain Harwich (data not shown). The repressive effect on $l a c Z$ activity was observed with transformants that contained IVS3-lacZ elements inserted on the $\mathrm{X}$ chromosome or on the autosomes. The presence of P-element DNA and not simply maternally deposited repressor protein or mRNA, is required for this repression of heterologous promoters, as the inheritance of cytoplasm only, and not of P-element DNA from Lk-
$\mathrm{P}(1 \mathrm{~A})$, did not cause repression (data not shown). In this experiment, a dominantly marked balancer $\mathrm{X}$ chromosome was used to follow the Lk-P(1A) chromosome. This maternal effect repression of $\mathrm{P}$ cytotype is characteristic and has also been observed with P-element promoterlacZ enhancer trap strains (Lemaitre et al. 1993). Taken together, these results demonstrate that P-cytotype repression is general and not restricted to the P-element promoter but can act on heterologous promoters when carried in P-element vectors.

The fact that repression of $l a c Z$ staining was observed with both the IVS 3 and $\Delta 2-3$ constructs suggested that loss of staining was attributable to transcriptional repression rather than effects on RNA splicing of IVS3. To determine directly whether this repression of staining was at the transcriptional level, RNA in situ hybridization was performed with ovaries from female progeny derived from the crosses described above. The distribution of RNA transcripts from the $\mathrm{P}\left[\mathrm{ry}^{+}{ }\right.$; hsp83-IVS3- $\beta$ geo] construct was examined using an antisense digoxygenin-labeled lacZ RNA probe /Gavis and Lehmann 1992). As seen in Figure 3A, the distribution of RNA transcripts parallels the lac $Z$ histochemical staining pattern, that is, staining in germ-line cells only (Fig. 2A). Ovaries of female progeny derived from the $\mathrm{P} \mid \mathrm{ry}^{+}$; hsp83-IVS3- $\beta$-geo] male $\times$ Lk-P(1A) female cross showed a dramatic reduction in the levels of lacZ mRNA (Fig. $3 \mathrm{C})$ to background levels seen for $r y^{50 \%}$, the transformation host (data not shown). In addition, the reciprocal cross of Lk-P(1A) males $\times \mathrm{P} \mid \mathrm{ry}^{+}$; hsp83-IVS3- $\beta$-geo] females did not show transcriptional repression (Fig. 3B). The RNA in situ hybridization results are consistent with the lacZ histochemical staining data and demonstrate that $\mathrm{P}$ cytotype repression can act on multiple heterologous promoters in the female germ line. Biochemical studies of the P-element transposase protein suggested that transcriptional repression might occur by interaction of $\mathrm{P}$-element repressor proteins with binding sites that overlap the P-element promoter (Kaufman and Rio 1991). However, the findings presented here would seem to rule out a simple repressor-operator interaction for P-cytotype transcriptional repression because (1) there are no binding sites for P-element proteins in the hsp83 and vasa promoter DNA fragments, and (2) although the P-element transformation vector carries the P-element promoter upstream of the heterologous promoters, transcriptional initiation from this promoter extending into the IVS3- $\beta$-geo transcription unit was not detected using reverse transcription-polymerase chain reaction (RT-PCR) with appropriate primers (data not shown). Therefore, more general chromatin or chromosomal mechanisms may be operating to effect the observed transcriptional repression of these maternal promoters (see Discussion).

\section{P cytotype does not repress heterologous promoters in somatic cells}

Previous genetic studies of repressor-producing $\mathrm{P}$ elements have shown that repression of both transposase 

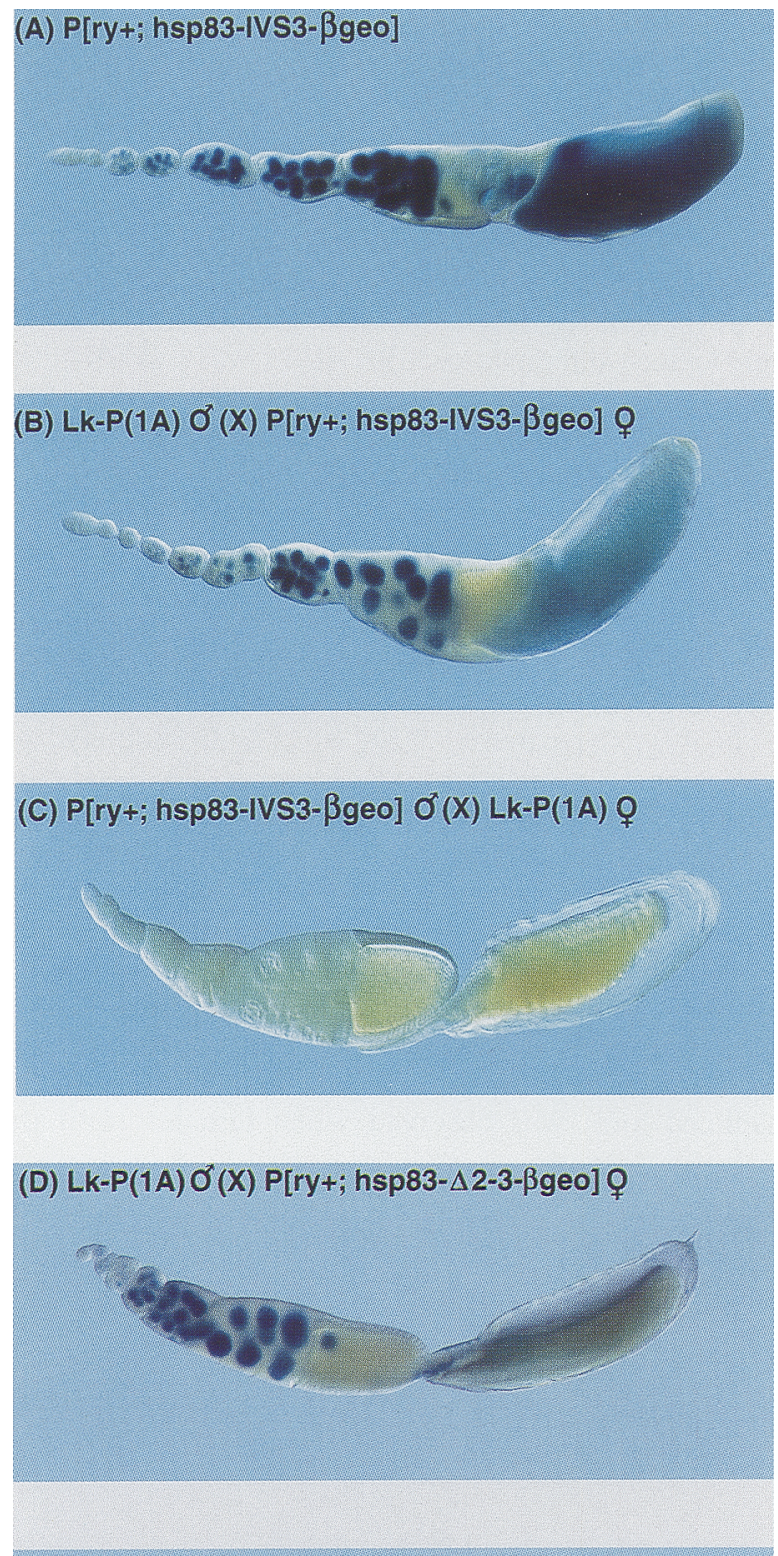

(E) $P\left[r y+\right.$; hsp83- $\Delta 2-3-\beta$ geo] $\sigma^{\prime}(x)$ Lk-P(1A)

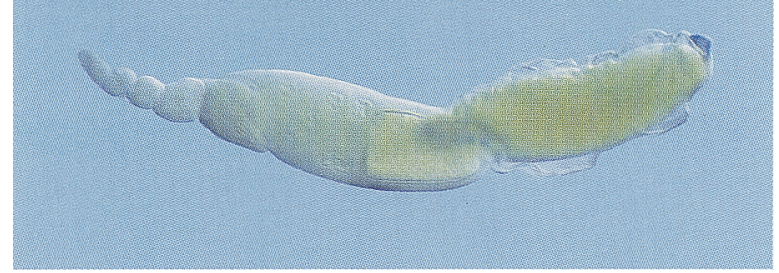

activity (Robertson and Engels 1989; Misra and Rio 1990) and expression of $\mathrm{P}-1 \mathrm{lac} Z$ genes in enhancer trap strains (Lemaitre and Coen 1991; Lemaitre et al. 1993) can occur in somatic as well as germ-line cells. However, in the soma repression of transposase activity and of $\mathrm{P}-l a c Z$ elements is zygotic, occurring regardless of which parent donates the repressor element, and does not exhibit the maternal effect characteristic of $\mathrm{P}$ cytotype (Misra and
Figure 2. Ovary $\operatorname{lac} Z$ staining in reciprocal genetic crosses. Ovaries from females derived from the indicated crosses are shown in each panel after fixation and lac $Z$ histochemical staining (see Materials and methods). (A) Parental $\mathrm{P}\left[\mathrm{ry}^{+}\right.$; hsp83IVS3- $\beta$-geo] ovary staining pattern. Staining occurs throughout all stages of oogenesis. $(B)$ Ovaries from $\mathrm{Lk}-\mathrm{P}(1 \mathrm{~A})$ males $\times \mathrm{P}\left[\mathrm{ry}^{+}\right.$; $h s p 83-I V S 3-\beta-g e o]$ females. No significant repression is observed. $(C)$ Ovaries from $\mathrm{P}\left[\mathrm{ry}^{+}\right.$; hsp83-IVS3- $\beta$-geo $]$ males $\times$ Lk$\mathrm{P}(1 \mathrm{~A})$ females. There is a complete loss of lac $Z$ staining. (D) Ovaries from Lk-P(1A) males $\times \mathrm{P}\left[\mathrm{ry}^{+}\right.$; hsp83- $\Delta 2-3-\beta-$ geo $]$ females. No significant repression is observed. The level of $l a c Z$ staining is comparable to that of the $\mathrm{P}\left[\mathrm{ry}^{+}{ } ;\right.$hsp83-IVS3- $\beta-$ geo $]$

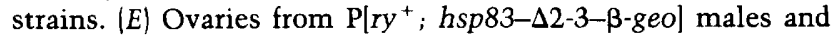
Lk-P(lA) females. There is a complete loss of lac $Z$ staining as observed with the $\mathrm{P}\left[\mathrm{ry}^{+}\right.$; $h$ sp83-IVS3- $\beta$-geo] strains. Note that

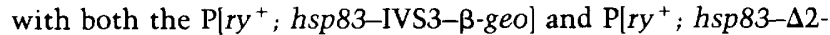
$3-\beta-g e o]$ strains some $l a c Z$ staining occurs in the somatic dorsal appendage tissue in both $M$ and $P$ cytotype. Occasionally, a few somatic follicle cells variably showed low but detectable lacZ activity in a minority of the ovaries examined.

Rio 1990; Robertson and Engels 1989; Lemaitre and Coen 1991). Therefore, it was of interest to examine whether the observed germ-line $\mathrm{P}$ cytotype transcriptional repression of heterologous promoters could also occur in somatic cells.

To test whether P cytotype would repress transcription from heterologous promoters in somatic cells, we used existing transformants carrying a $5.2-\mathrm{kb}$ upstream DNA fragment from the even-skipped (eve) pair-rule segmentation gene fused to the $E$. coli $\beta$-galactosidase gene $(l a c Z)$. This construct expresses $\operatorname{lac} Z$ in three $(2,3$, and 7) of the seven normal eve stripes in the early embryo (Harding et al. 1989). We used the eve 5.2-kb lacZtransformed strain in reciprocal crosses to the $\mathrm{Lk}-\mathrm{P}(1 \mathrm{~A})$ P-cytotype strain. In both cases, no repression of evelacZ staining was observed (Fig. 4A,B) using a 0 - to $12-\mathrm{hr}$ embryo collection. We have also observed a failure of Lk-P(lA) to repress other somatically active promoterlacZ fusions, such as a twist-lacZ fusion (Jiang et al. 1991; data not shown). This result indicates that although the Lk-P(1A) strain is capable of repressing transcription from both P-element (Lemaitre et al. 1993) and heterologous promoters in the female germ line, it is incapable of repressing heterologous promoters expressed in the soma. This germ-line restriction may be relevant to the maternal effect and inheritance characteristic of $P$ cytotype.

\section{$P$ cytotype causes a reduction in RNA splicing of the P-element IVS3}

The discovery that the P-element IVS3 was removed only in the germ line (Laski et al. 1986) and that synthesis of the $66-\mathrm{kD}$ repressor required IVS retention (Rio et al. 1986) suggested that control of IVS3 splicing in the germ line might provide a means to positively feed back repressor synthesis (O'Hare and Rubin 1983). More recently, studies examining the repressor elements in $P$ strains (O'Hare et al. 1992) and germ-line repression of 


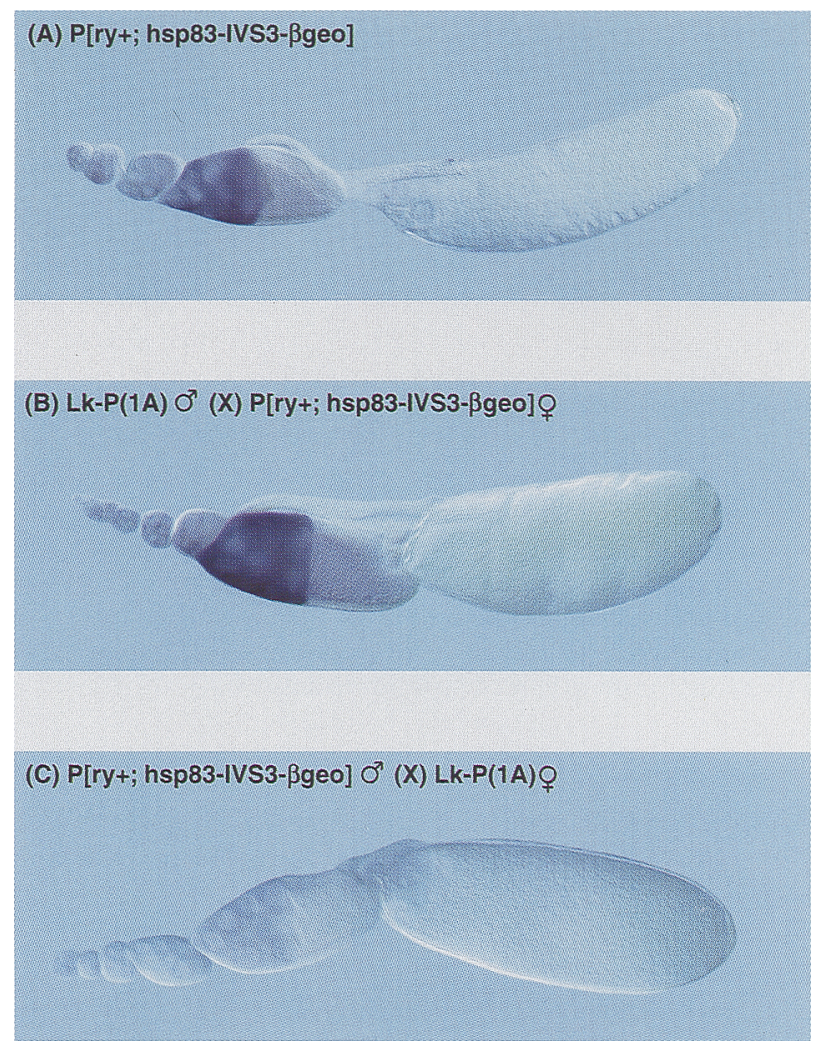

Figure 3. Ovary whole-mount RNA in situ hybridization in reciprocal genetic crosses. Ovaries from females derived from the indicated crosses are shown in each panel after fixation and in situ hybridization, with an antisense $l a c Z$ probe and antibody detection (see Materials and methods). (A) Parental $\mathrm{P} \mid r y^{+}$; hsp83-IVS3- $\beta$-geol ovary RNA in situ hybridization. Staining is prominent in the stage $10 \mathrm{egg}$ chamber yet can be observed in the early stages of oogenesis. $(B)$ Ovaries from Lk-P(1A) males $\times \mathrm{P}\left[\mathrm{ry}^{+}\right.$; hsp83-IVS3- $\beta$-geo $]$ females. No significant repression is observed. $(C)$ Ovaries from $\mathrm{P} \mid \mathrm{ry}^{+}$; hsp83-IVS3- $\beta$ $\mathrm{geo}$ males $\times \mathrm{Lk}-\mathrm{P}(1 \mathrm{~A})$ females. There is a background level of staining comparable to the level seen in the untransformed $r y^{506}$ strain (data not shown).

P-lacZ elements (Lemaitre et al. 1993) have suggested that $P$ cytotype might influence IVS3 splicing as a means to feed back $66-\mathrm{kD}$ repressor synthesis. Because the $\mathrm{P}\left[\mathrm{ry}^{+} ;\right.$hsp83-IVS3- $\beta$-geo $]$ and $\mathrm{P}\left[\mathrm{ry}^{+} ;\right.$vasa-IVS3- $\beta$-geo $]$ reporter constructs are only transcribed in germ-line cells of the egg chamber, they could be used to directly examine the effects of P cytotype on splicing of IVS3 in the female germ line. Previous IVS3 reporter genes were transcribed both in somatic and germ-line cells, as are natural and transformed full-length $P$ elements (Laski and Rubin 1989). Thus, in these earlier experiments it was not possible to examine the effects of cytotype on IVS3 splicing without the ambiguity caused by the presence of somatic, unspliced, IVS3-retaining mRNA. Given the germ-line-specific patterns of lac $Z$ activity and mRNA distribution of the $\mathrm{P}\left[\mathrm{ry}^{+} ;\right.$hsp83-IVS3- $\left.\beta-\mathrm{geo}\right]$ construct (Figs. 2 and 3), we could, for the first time, analyze the effect of P cytotype on IVS 3 splicing in the germ line in vivo. Total RNA was isolated from dis- sected ovaries and subjected to RT-PCR analysis, using primers that were specific for the fusion gene (see Materials and methods).

Analysis of RNA isolated from the $\mathrm{P}\left[\mathrm{ry}^{+}\right.$; hsp83IVS3- $\beta$-geo] strain showed that there were two cDNA fragments of 155 and $344 \mathrm{bp}$ (Fig. 5A, lane 3), the sizes expected for spliced (Fig. 5A, lane 18) and unspliced (Fig. $5 A$, lane 17) IVS3- $\beta$-geo mRNA, respectively. The identity of these DNA fragments as corresponding to accurately spliced and unspliced IVS3 RNA was confirmed by the subcloning and sequencing of the PCR products (data not shown). No PCR products were obtained without reverse transcription (Fig. 5A, lane 4). The presence of two cDNA fragments demonstrates that IVS3 is spliced incompletely during oogenesis. RNA samples were then prepared from ovaries of progeny from reciprocal crosses between Lk-P(1A) and $\mathrm{P}\left[\mathrm{ry}^{+}\right.$; hsp83-IVS3- $\beta$-geo $]$. As expected, ovarian mRNA from Lk-P $(1 \mathrm{~A})$ males $\times \mathrm{P} \mid \mathrm{ry}^{+}$; hsp83-IVS3- $\beta$-geol females showed the same pattern by RT-PCR as the parental $\mathrm{P}\left[\mathrm{ry}^{+}\right.$; hsp83-IVS3- $\beta$-geo $]$ females alone (Fig. 5A, lane 5). However, RNA samples from ovaries of progeny from reciprocal $L k-P(1 A)$ females crossed to $\mathrm{P}\left[\mathrm{ry}^{+}\right.$; hsp83-IVS3- $\beta$-geo $]$ males showed an altered ratio of the unspliced ( $344 \mathrm{bp}$ ) to spliced (155 bp) cDNA fragments (Fig. 5A, lane 7), such that the spliced form of the RNA was reduced dramatically. These samples were prepared from ovaries in which hsp83-IVS3$\beta$-geo transcription was repressed by $\mathrm{P}$ cytotype (see above). The same shift in splicing of IVS3 to favor the unspliced form was observed when females from the

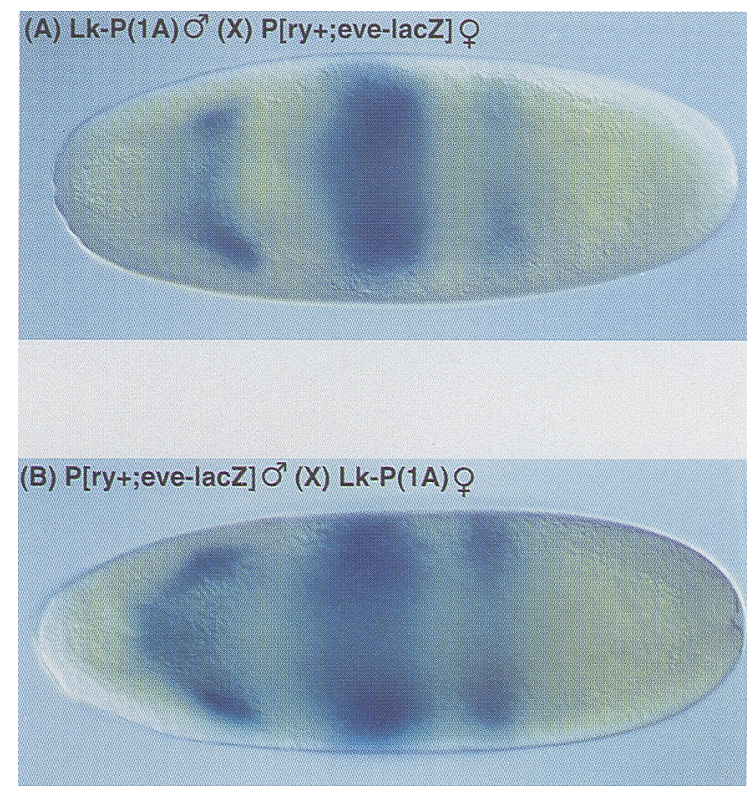

Figure 4. lacZ histochemical staining of $\mathrm{P}\left[\mathrm{ry}^{+}\right.$; eve-lacZ $]$embryos in reciprocal crosses. $(A)$ Embryos from Lk-P $(1 \mathrm{~A})$ males $\times$ $\mathrm{P}\left[\mathrm{ry}^{+}\right.$; eve-lacZ] females. (B) Embryos from $\mathrm{P}\left[\mathrm{ry}^{+}\right.$; eve-lacZ $]$ males $\times$ Lk-P $(1 \mathrm{~A})$ females. No detectable difference is observed with eve stripes 2,3 , and 7, which are visible in both cases. These embryos are germ-band elongation stage, $\sim 4 \mathrm{hr}$ old. A dorsal view is shown. No effect of P cytotype on eve-lacZ staining was observed with either earlier or later stage embryos. 

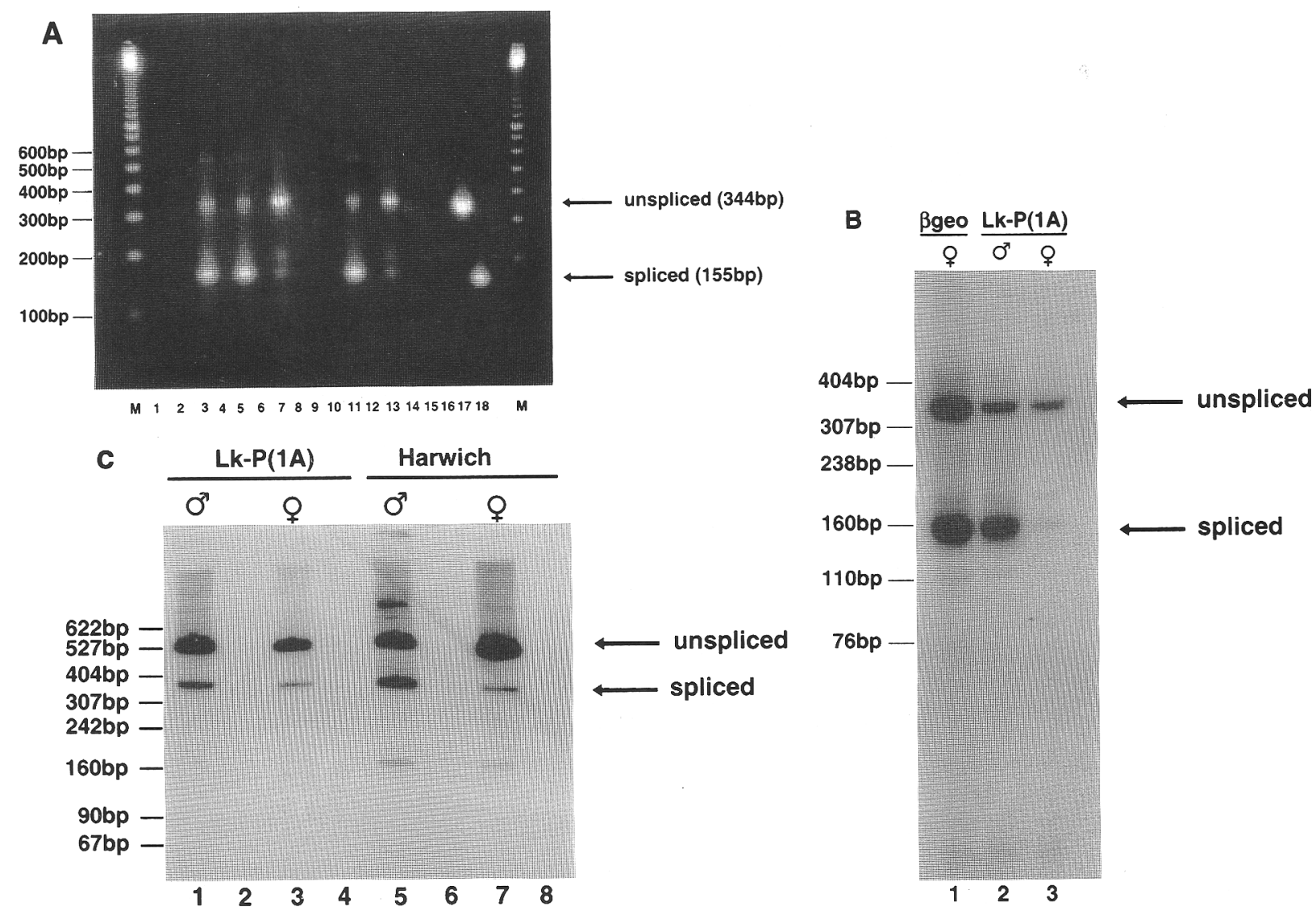

Figure 5. Analysis of ovary RNA from reciprocal crosses using RT-PCR. (A) Ethidium bromide-stained gel analyses of RT-PCR products. Reactions were performed either in the presence (lanes $1,3,5,7,9,11,13,15)$ or absence $($ lanes $2,4,6,8,10,12,14,16)$ of reverse transcriptase. RNA samples were from Lk-P(1 A) female ovaries (lanes 1,2), P|ry ' ; hsp83-IVS3- $\beta$-geo| ovaries (lanes 3,4), ovaries from Lk-P(1A) males $\times \mathrm{P} \mid r y^{+}{ }^{;}$, hsp83-IVS3- $\beta$-geo $)$ females (lanes 5,6$)$, ovaries from $\mathrm{P} \mid$ ry ${ }^{+} ;$, $h$ sp83-IVS3- $\beta$-geol males $\times$ Lk-P(1A) females $($ lanes 7,8 ), ovaries from Harwich females (lanes 9,10), ovaries from Harwich males $\times \mathrm{P} \mid$ ry ${ }^{+}$; hsp83-IVS3- $\beta$-geo] females (lanes 11,12 ), ovaries from $\mathrm{P}\left\{\mathrm{ry}^{+}\right.$; hsp83-IVS3- $\beta$-geo males $\times$ Harwich females (lanes 13,14$)$, ry ${ }^{506}$ ovaries (lanes 15,16), and plasmid DNA controls corre-

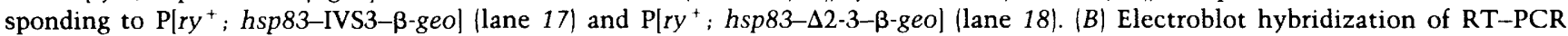

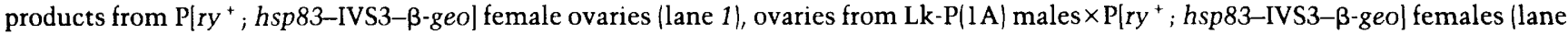
$2)$, and $\mathrm{P} \mid r y^{+}$; hsp83-IVS3- $\beta$-geol males $\times$ Lk-P(1A) females (lane 3). (C) Electroblot hybridization of RT-PCR products from the $\mathrm{Lk}-\mathrm{P}(1 \mathrm{~A})$ and Harwich P strains. RNA was isolated from ovaries from Lk-P(1A) males $\times \mathrm{P}\left[\right.$ ry ${ }^{+} ;$hsp83-IVS3- $\beta$-geo females $(\mathrm{lanes} 1,2)$;

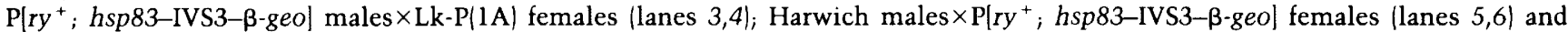
$\mathrm{P}\left[\mathrm{ry}^{+}{ }^{+}\right.$, hsp83-IVS3- $\beta$-geo) males $\times$ Harwich females (lanes 7,8$)$. Reactions were performed either with (lanes $\left.1,3,5,7\right)$ or without (lanes $2,4,6,8)$ reverse transcription. The sizes of spliced and unspliced RT-PCR products are indicated as are the sizes of DNA molecular mass standards (in bp).

P-strain Harwich were mated to $\mathrm{P}\left[\mathrm{ry}^{+}\right.$; hsp83-IVS3- $\beta$ geo] males (Fig. 5A, lane 13) but not in the reciprocal cross (Fig. 5A, lane 11). No cDNA fragments were observed from the Lk-P(1A) strain alone (Fig. 5A, lane 1) or without the inclusion of reverse transcriptase (Fig. 5A, lanes $2,4,6,8,10,12,14,16)$. The identity of the cDNA products as well as the shift in IVS3 splicing was confirmed by blot hybridization analysis with a P-element DNA probe (Fig. 5B). In this experiment the PCR parameters were optimized to be in the linear range of the amplification reaction (see Materials and methods), and here, again, the same shift to unspliced IVS3 RNA occurs when transcription is repressed. No cDNA fragments were observed using ovary RNA from the $r y^{506}$ strain, the injection host for the $\mathrm{P}\left[\mathrm{ry}^{+}\right.$; hsp83-IVS3- $\beta$ geol transformants (Fig. 5A, lane 15). These findings in- dicate that transcriptional repression results in a reduction of IVS3 splicing, as the unspliced IVS3-retaining mRNA is the predominant form. Furthermore, this shift in splicing following transcriptional repression in $\mathrm{P}$ cytotype also occurs with endogenous $P$ elements in both the Harwich and Lk-P $(1 \mathrm{~A})$ strains as assayed by RT-PCR (Fig. 5C). In this experiment, ovarian RNA from female progeny of reciprocal crosses between either the Harwich (Fig. 5C, lanes 5-8) or Lk-P(1A) (Fig. 5C, lanes 1-4) $\mathrm{P}$ strains and the $\mathrm{M}$ strains carrying the $\mathrm{P}\left[\mathrm{ry}^{+}\right.$; hsp83IVS3- $\beta-g e o$ l reporter construct was analyzed by RT-PCR using P-element-specific primers flanking the third intron (see Materials and methods). In both cases, when P-strain females are used, ovary RNA contains less IVS3spliced P-element mRNA relative to unspliced premRNA (Fig. 5C, cf. lanes 1 and 3 for Lk-P(1A) and lanes 
5 and 7 for Harwich). No cDNA products were observed in the absence of reverse transcription (Fig. 5C, lanes $2,4,6,8)$. However, it is important to realize that these RNA samples contain somatic follicle cell P-element RNA that may provide additional unspliced IVS3 P-element mRNA, unlike the hsp83-IVS3- $\beta$-geo reporter RNA analyzed above. Nonetheless, it is apparent from these results that the IVS3 splicing shift to unspliced pre-mRNA in P cytotype is not peculiar to the IVS3- $\beta$ geo reporter transgenes. Note that this analysis relies on the relative amounts of spliced and unspliced RNA in a given sample and not on a comparison between different samples. Analysis of the levels of RNA by in situ hybridization suggests that only background levels of $h s p 83$ IVS3- $\beta$-geo RNA are present in ovaries derived from $L k$ $\mathrm{P}(1 \mathrm{~A})$ females crossed to $\mathrm{P}\left[\mathrm{ry}^{+}\right.$; hsp83-IVS3- $\beta$-geo males (Fig. 3; see above), indicating that the RT-PCR analysis is much more sensitive than whole-mount in situ hybridization. This reduction of IVS3 splicing in the presence of $\mathrm{P}$ cytotype provides a mechanism for the autoregulatory nature of $P$ cytotype (Fig. 6). P cytotype would lead to transcriptional repression of P-element pre-mRNA synthesis. When transcription is low, removal of IVS3 is dramatically reduced leading to increased production of unspliced $66-\mathrm{kD}$ repressor-producing mRNA relative to spliced transposase mRNA. This would lead to increased deposition of the repressor mRNA and/or protein in P-strain oocytes during oogenesis and maintenance of $\mathrm{P}$ cytotype in subsequent generations (Misra and Rio 1990;
Rio 1991). However, in M cytotype, there would be an absence of transcriptional repression, and at high levels of pre-mRNA IVS3 splicing occurs resulting in transposase production and hybrid dysgenesis. These findings, taken together with previous genetic data (Lemaitre et al. 1993), provide an explanation for the germ-line-specific maternal autoregulation of $66-\mathrm{kD}$ P-element repressor production characteristic of $\mathrm{P}$ cytotype.

\section{Discussion}

Germ-line autoregulation of 66-kD P-element repressor in $P$ cytotype involves a combination of transcriptional repression and reduction of third intron splicing

One of the puzzling aspects of genetic analysis of P-cytotype control is that repressor synthesis would require a positive feedback to maintain the $\mathrm{P}$ cytotype in subsequent generations (Engels 1983; O'Hare and Rubin 1983). The discovery of the germ-line-specific splicing of IVS3 (Laski et al. 1986) suggested that IVS3 splicing might be a target for autoregulation. However, it was also observed that if transposase was produced somatically or in the germ line, $\mathrm{P}$ cytotype or the $66-\mathrm{kD}$ repressor could operate to repress transposase activity even in the absence of IVS3 splicing (Robertson and Engels 1989; Misra and Rio 1990). Therefore, although splicing of IVS3 in the germ line was a logical way to increase repressor
Figure 6. Effect of cytotype on the P element pre-mRNA. The schematic drawing indicates that transcription is high in $M$ cytotype, and IVS3 splicing occurs to encode both $66-\mathrm{kD}$ repressor and $87-\mathrm{kD}$ transposase mRNAs. Transcription is repressed in $\mathbf{p}$ cytotype, and IVS 3 splicing is reduced and a higher proportion of 66$\mathrm{kD}$ mRNA is produced. This leads to an autoregulatory loop for synthesis of the $66-\mathrm{kD}$ repressor protein.

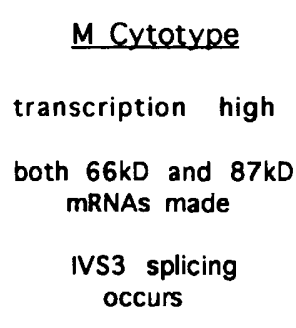

\section{P Cytotype}

transcription

repressed

66kD mRNA made

IVS3 splicing inhibited

\section{$2.9 \mathrm{~kb} \mathrm{P}$ Element}
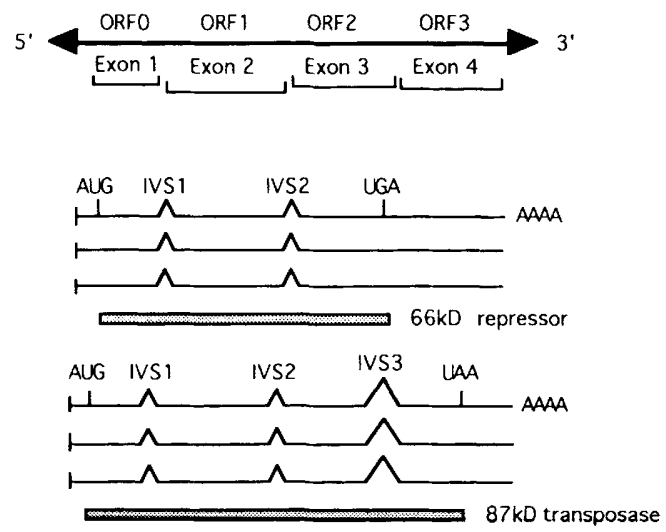

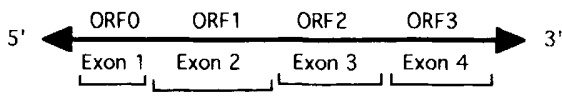
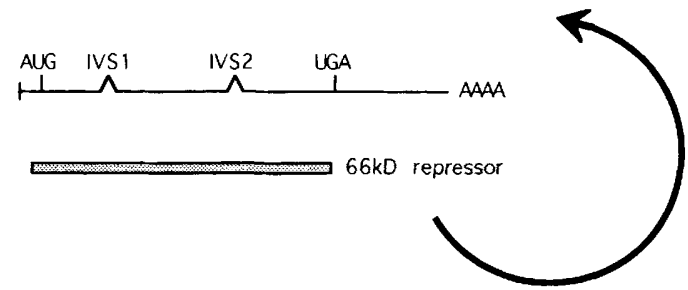

autoregulatory loop 
synthesis, it was not essential for repression of transposase by $\mathrm{P}$ cytotype in the germ line or the soma.

The discovery of strong P cytotype strains with several complete $\mathrm{P}$ elements allowed a detailed genetic analysis of the inheritance and mode of action of P cytotype (Ronsseray et al. 1991). Other studies suggested that one aspect of P-cytotype repression involved transcriptional repression (Lemaitre and Coen 1991). However, these studies did not provide insight into a means to autoregulate the levels of the $66-\mathrm{kD}$ repressor. Analysis of the structures and distribution of $P$ elements in the $P$ strain $\pi 2$ led to the proposal that perhaps IVS3 might be a target for autoregulation of repressor synthesis in the germ line because each major chromosome arm was required for determining P cytotype (Engels 1983, 1989) and carried multiple complete $\mathrm{P}$ elements (O'Hare et al. 1992). Genetic studies also suggested that control of IVS3 splicing in the germ line might provide a means to increase the production of $66-\mathrm{kD}$ repressor in the $\mathrm{P}$ cytotype (Lemaitre et al. 1993).

The studies presented here directly test the proposal of Lemaitre et al. (1993) and O'Hare et al. (1992) that transcriptional repression in the female germ line might lead to alteration in IVS3 splicing such that more $66-\mathrm{kD}$ repressor protein would be made in P cytotype. Using maternally expressed germ-line-specific promoters, reporter transcripts containing IVS3 could be assayed without confusion from somatically derived P-element transcripts. Our findings provide direct support for the idea that autoregulation of the $66-\mathrm{kD}$ repressor can occur in the germ lines of P-cytotype females through a combination of transcriptional repression and retention of IVS3 such that when P-element transcription is repressed essentially all of the remaining P-element mRNA retains IVS3 (Fig. 6).

When P cytotype causes transcriptional repression of a gene carrying the P-element IVS3, IVS3 splicing is reduced. This shift in splicing could be the result of a negative splicing factor that is present in limiting amounts in the cell, thus preventing IVS3 removal. High levels of P-element pre-mRNA in $M$ cytotype would titrate this factor allowing IVS3 splicing and transposase production. One candidate for such a factor is an RNA-binding protein called PSI, which acts to repress IVS3 splicing in vitro (Siebel et al. 1994). This protein is expressed at high levels only in somatic cells where IVS3 splicing is completely inhibited and is present at much lower or undetectable levels in the germ line (Siebel et al. 1995). Biologically, this mechanism seems plausible because the full-length $P$ element can encode both transposase and repressor proteins, so that after fertilization of P-cytotype eggs, the presence of maternally deposited $66-\mathrm{kD}$ repressor would cause a repression of P-element transcription and then IVS3 retention would continue to allow production only of repressor-producing mRNA from the reduced levels of P-element pre-mRNA synthesized. In $M$ cytotype, in the absence of maternally derived 66$\mathrm{kD}$ repressor, high levels of P-element pre-mRNA would allow the synthesis of both transposase and repressor mRNAs. This finding would explain how repressor production could lead to an autoregulatory loop for repres- sor mRNA synthesis (Fig. 6), how it could increase the levels of $66-\mathrm{kD}$ repressor relative to transposase in $\mathrm{P}$ cytotype, and why both maternal repressor as well as fulllength $\mathrm{P}$ elements would be required for the multigenerational inheritance of $P$ cytotype (see below).

A link between transcriptional repression and premRNA splicing patterns has not been observed previously. However, because transcriptional repression can occur in tissue-specific and temporal patterns (Herschbach and Johnson 1993; Rio 1993), it is possible that in addition to reducing transcription, different protein isoforms could be generated by altering splicing patterns of the reduced levels of pre-mRNA. Cell biological studies have shown that in eukaryotic nuclei, sites of transcription and pre-mRNA processing may be coincident (Beyer and Osheim 1988; Jiménez-García and Spector 1993). Therefore, alterations in pre-mRNA levels via transcriptional repression might alter the distribution of splicing factors on the reduced levels of pre-mRNA synthesized at these sites, thereby leading to alteration of splicing patterns. There is also direct evidence that splicing can occur on nascent pre-mRNA transcripts (LeMaire and Thummel 1990; Huang and Spector 1991; Xing and Lawrence 1993) so the idea of alterations in pre-mRNA levels leading to different distributions of splicing factors is certainly a plausible means to alter splicing patterns.

P-cytotype transcriptional repression in the female germ line occurs with heterologous promoters, implying a chromatin-based mechanism

Our results indicate that $\mathrm{P}$ cytotype acts during oogenesis to cause transcriptional repression of the maternal $h s p 83$ and vasa promoters carried in P-element vectors. Previous studies have shown a repressive effect of $\mathrm{P}$ cytotype only on transcription from the P-element promoter when it was fused to the E. coli lacZ gene in enhancer trap P-element constructs (Lemaitre and Coen 1991). These studies suggested that transcriptional repression might be brought about by a simple repressoroperator interaction in which the $66-\mathrm{kD}$ P-element repressor protein might interact with the transposasebinding site near the $5^{\prime}$ end of P-element DNA that overlaps the TATA box (Kaufman and Rio 1991). A similar mechanism has been shown to operate in mammalian cells for repression of SV40 early gene transcription by the large $\mathrm{T}$ antigen (Tiian 1981). This is a common mechanism of transcriptional repression in prokaryotes as well as eukaryotes (Herschbach and Johnson 1993). However, the findings presented here, namely that $\mathrm{P}$ cytotype can function to repress two different heterologous promoters carried in P-element vectors and lack binding sites for P element proteins near the transcriptional initiation site suggest that a more general mechanism must be operating. A link between chromatin and P-cytotype repression was made previously when P-element repressor had been shown to enhance the trans-inactivating effects of the zeste ${ }^{1}$ allele on a modified white transgene (Coen 1990). Perhaps interactions of the P-element repressor protein(s) with chromatin-associated or chromo- 
some structural proteins might be involved in cytotype transcriptional repression. For instance, the interaction of P-element repressor proteins with sites in the P-element vector could, in conjunction with chromatin-associated proteins, lead to an inactive chromatin conformation that effects transcription from downstream promoters carried inside $P$ elements.

The finding that an interaction occurs between a negative transcriptional regulator and chromatin-associated proteins or chromosome structural proteins has been observed previously in both Drosophila and yeast. In Drosophila, the Polycomb $(\mathrm{PC})$ group genes serve a maintenance role by repressing homeotic gene expression during development (Paro 1990). The Polycomb protein shares sequence homology with HP1, a heterochromatin protein encoded by the Su(var)205 gene, which can modify position effect variegation (PEV) (Paro 1990). Moreover, biochemical studies have shown that Polycomb protein is found in large protein complexes that are chromatin components (Frankel et al. 1992). In yeast, the swi/snf and $s p t / s i n$ gene products form protein complexes that are chromatin components and function to alter gene transcription (Winston and Carlson 1992; Carlson and Laurent 1994). Therefore, it is likely that P-cytotype repression might involve an interaction of the P-clement repressor proteins with chromatin-associated proteins, some of which might be germ line-specific.

\section{A role for full-length $P$ elements in P cytotype}

The effect of transcriptional repression by $\mathrm{P}$ cytotype on P-element IVS 3 splicing that we have observed provides an explanation for why the maternal effect of $P$ cytotype appears to be restricted to the germ line (Lemaitre and Coen 1991; Lemaitre et al. 1993). If the effects of cytotype transcriptional repression ultimately feed back to allow increased IVS3 retention and increased production of the $66-\mathrm{kD}$ repressor, then this autoregulatory loop would be limited to the germ line, where IVS3 splicing exclusively occurs. This idea is also consistent with the observation that in somatic tissues cytotype repression occurs zygotically with no evidence of a maternal effect (Misra and Rio 1990; Lemaitre and Coen 1991). Furthermore, in somatic cells, P cytotype or the $66-\mathrm{kD}$ repressor can function to repress transposition even when no IVS3 splicing occurs, so IVS3 splicing is not absolutely required for repressor function (Robertson and Engels 1989; Misra and Rio 1990|. These data are also consistent with genetic experiments defining a maternal pre-P cytotype, a repressor activity that could function for one generation when transmitted to oocytes without inheritance of P-element DNA but that could not produce the maternal inheritance of $P$ cytotype on its own (Ronsseray et al. 1993). The multigenerational maternal inheritance of $\mathrm{P}$ cytotype requires both the maternal pre- $\mathrm{P}$ cytotype and introduction of complete, full-length $\mathrm{P}$ elements with the paternal gametes (Ronsseray et al. 1993). This result suggests that without full-length P elements there would be no propagation of repression after maternally deposited repressor was exhausted. Our data directly demonstrate that transcriptional repression by $\mathrm{P}$ cytotype can alter IVS3 splicing and presumably lead to increased $66-\mathrm{kD}$ repressor production. This transcriptional repression would be necessary because high levels of $\mathbf{P}$ element pre-mRNA in the germ line might be refractory to the normal inhibition of IVS3 splicing that occurs in somatic cells by the action of the splicing factor PSI (Siebel et al. 1994), which may be present at much lower levels in the germ line (Siebel et al. 1995; M.D. Adams and D.C. Rio, unpubl.).

The mechanism outlined above provides an explanation for how P cytotype might be propagated from generation to generation and why it can only be inherited through the female germ line. Early models to explain the inheritance of $\mathrm{P}$ cytotype proposed that repressor synthesis must be autoregulatory (Engels 1983; O'Hare and Rubin 1983) and must persist for multiple generations. The combination of transcriptional repression and regulation of IVS3 splicing provides a means to increase $66-\mathrm{kD}$ repressor production, reduce transposase synthesis, and simultaneously produce a maternal factor 166 $\mathrm{kD}$ repressor $\mathrm{RNA}$ or protein) that could be incorporated into unfertilized P-strain oocytes. This model, although appealing, cannot serve to explain why no strict correlation between $66-\mathrm{kD}$ repressor production and maternal inheritance of cytotype has been observed (Gloor et al. 1993; Misra et al. 1993). Perhaps, the genomic position of repressor-producing $P$ elements may influence their ability to participate in the germ-line-specific autoregulatory loop described above (Misra et al. 1993). The molecular nature of the factor involved in the pre-P cytotype maternal effect will shed light on how the mechanism of cytotype repression operates.

\section{Materials and methods}

Recombinant DNA and Drosophila germ line transformation

Three transformation constructs were generated carrying the vasa or hsp 83 promoters fused to the IVS3- $\beta$-geo-coding sequence. All three were made as subclones in the plasmid vector pHSX (Jones and Rubin 1990) and transferred to the Drosophila transformation vector pDm30 (Mismer and Rubin 1987) as NotI DNA fragments. The transformation vector $\mathrm{pDm} 30$ carries the standard P-element vector DNA sequences from Carnegie 3: 1-585 and 2685-2907 (Rubin and Spradling 1983; Ashburner 1989). The $h s p 83$ promoter DNA fragment was a $1.1-\mathrm{kb}$ DNA fragment amplified from plasmid pCAT82 (Gavis and Lehmann 1992) using PCR (Sambrook et al. 1989) with the following primers: 5' $\left(5^{\prime}\right.$-CGCGCGGATCCTTAACCGGGACC-3') and 3'-(5'-CGCGCCTGCAGGTCCTCCACCTTGCGCTTCTTCT-

TGGGGGGGGTGGGCATTTTCGTATGTATGTTTTTCGTTC-3') carrying the ATG codon, translation start site (Cavener 1987), and NLS and inserted as a BamHI-Pst I fragment into pBSIIKS $(+)$ (Stratagene). The IVS3 and $\Delta 2-3$ DNA fragments were obtained from $\mathrm{P}\left[\mathrm{ry}^{+}\right.$; hsp $70-\mathrm{P}(1911-2150-\mathrm{lacZ})$ and $\mathrm{P}\left[r y{ }^{+}\right.$; $h s p 70-\mathrm{P}(1911-\Delta 2-3-2183)-$ lacZ], respectively (Laski and Rubin 1989), as 1.0- and 0.8-kb PstI-ClaI DNA fragments that also carried part of the $\beta$-galactosidase gene. The $3^{\prime}$ half of $\beta$-galactosidase, the neo fusion, and a bovine growth hormone poly (A) signal were contained on a $3.4-\mathrm{kb}$ ClaI-Xhol DNA fragment from plasmid pPGK $\beta$-geobpA (Friedrich and Soriano 1991) 
obtained from Philipe Soriano. These three DNA fragments (hsp83, IVS, or $\Delta 2-3$ and $\beta$-geo) were ligated to the $\mathrm{pHSX}$ vector cleaved with $\mathrm{BamHI}$ and $\mathrm{XhoI}$ in a four-way ligation. Clones were screened by colony hybridization and restriction endonuclease analysis (Sambrook et al. 1989). The vasa promoter fragment was obtained from plasmid pBSKS|+1-vasa (Misra et al. 1993) as a 9.9-kb NotI, Klenow-treated, HindIII DNA fragment, and the ATG-NLS-IVS3- $\beta$-geo DNA fragment was obtained as a 4.5 -kb $X$ baI partial, Klenow-treated, Xhol fragment from the pHSX-hsp83-IVS3- $\beta$-geo plasmid described above. Again, the vasa and IVS3- $\beta$-geo DNA fragments were ligated to the pHSX vector cleaved with HindIII and $X h o I$ in a three-way ligation. The resulting $14.4-\mathrm{kb}$ vasa-IVS3- $\beta$-geo DNA fragment was inserted into the NotI site of $\mathrm{pDm} 30$.

Germ-line transformation of Drosophila strain $r y^{506}$ was carried out using standard microinjection methods with bleach dechorionation (Spradling 1986). Plasmid DNA was prepared for injection by standard procedures (Spradling and Rubin 1982), and $\mathrm{ry}^{+}$transformant lines were genetically mapped and balanced (Spradling 1986; Ashburner 1989).

\section{Histochemical lacZ assays and in situ hybridization}

lacZ histochemical stainings on whole-mount 0- to 12 -hr embryo collections were performed as described (Grossniklaus et al. 1989). lac $Z$ whole-mount ovary stainings were performed as described (O'Kane and Gehring 1987) on hand-dissected ovaries. RNA in situ hybridizations to whole-mount ovaries were performed as described (Jiang et al. 1991; Gavis and Lehmann 1992) with a few modifications. An antisense $l a c Z$ digoxygenin-labeled RNA probe was used at a hybridization temperature of $55^{\circ} \mathrm{C}$ and hybridized to ovaries for $24-30 \mathrm{hr}$. The unbound probe was removed by washing the ovaries in hybridization buffer for $5 \mathrm{hr}$ with at least six to eight changes of buffer. The hybridization buffer was removed by washing with solutions containing decreasing amounts of buffer and increasing amounts of PBS/ $0.5 \%$ Triton $\mathrm{X}-100$ over $\sim 1 \mathrm{hr}$. Stained ovaries were mounted in $70 \%$ glycerol/PBS. The lac $Z$ RNA probe was made by in vitro transcription of EcoRI-cleaved pGEM4-lacZ using T7 RNA polymerase (Jiang et al. 1991; Gavis and Lehmann 1992).

\section{RNA isolation and RT-PCR analysis}

Ovaries (50-100 $\mu \mathrm{l})$ were dissected from 3- to 4-day-old well-fed females. Ovary samples were frozen in liquid nitrogen and stored at $-80^{\circ} \mathrm{C}$. Total RNA was isolated by extraction with guanidinium thiocyanate and high speed centrifugation in a CsCl gradient as described (Ausubel et al. 1987; Sambrook et al. 1989|. Samples were spun in a Beckman tabletop ultracentrifuge at $40,000 \mathrm{rpm}$ in a swinging bucket rotor for $12 \mathrm{hr}$. The RNA was then treated with DNaseI as described (Ausubel et al. 1987; Sambrook et al. 1989).

DNase I-treated total ovary RNA $(2 \mu \mathrm{g})$ was reverse transcribed using Moloney murine leukemia virus (M-MLV) reverse transcriptase and 25 pmoles of the downstream lac $Z$ primer. Reactions were carried out as described (Ausubel et al. 1987; Sambrook et al. 1989). Ten percent of the reverse transcriptase reaction was amplified in a standard PCR reaction containing 12.5 pmoles each of both the downstream $\left(3^{\prime}-\beta\right.$-gal $)$ and upstream $\left(5^{\prime}\right.$-NLS) primers, using an annealing temperature of $69^{\circ} \mathrm{C}$. The primer sequence for $3^{\prime}-\beta$-gal is $5^{\prime}$-GGGAAGCTTGGTAACGCCAGGGTTTTCCCACTCACG-3', and that for $5^{\prime}$ NLS is 5'-CCCGAATTCATGCCCACCCCCCCCAAGAAGAAGCGC-3'. cDNA amplification products were analyzed on a $2 \%$ NuSieve 3:1 agarose gel. Samples whose products were not detectable on an agarose gel were analyzed by electroblotting from an $8 \%$ native polyacrylamide gel onto a positively charged nylon (Hybond- $\mathrm{N}^{+}$) membrane, as described (Ausubel et al. 1987). Electroblotted membranes were probed with an $\alpha-{ }^{32} \mathrm{P}$ labeled dCTP random hexamer-primed P-element IVS3 DNA probe (Ausubel et al. 1987). To make the PCR reactions quantitative, serial dilutions of the reverse transcription reactions were made and PCR was performed for 20 cycles instead of 30 . The PCR reactions were then electroblotted. The electroblot was hybridized with a ${ }^{32}$ P-labeled IVS3 probe and then analyzed by PhosphorImaging. For analysis of Lk-P(1A) and Harwich P-element RNAs, RT-PCR was performed with primers complementary to exon sequences flanking the P-element IVS3. The sequence for the downstream primer, 1A 2289, is 5'-GCTTAACATCTCATCGACAGGCTCATCATCG-3', and that for the upstream primer, lA 1749, is 5'-GGTATCATTGTGAATAATGCTTCGCTTGATGG-3'. The reverse transcription reactions were performed with primer 1A 2289 and $8 \mu \mathrm{g}$ of total RNA for Lk-P $\mid 1 \mathrm{~A}\}$ and $2 \mu \mathrm{g}$ RNA for Harwich. Forty percent of the reverse transcription reaction was amplified in a $25 \mu l$ PCR reaction using both upstream and downstream P-element primers. Ten microliters of each PCR reaction was loaded onto a $7 \%$ polyacrylamide gel, which was then electroblotted and probed with a full-length radiolabeled P-element DNA probe.

\section{Acknowledgments}

We thank M. Levine for providing the eve-lacZ and twist-lacZ transformants and a whole-mount RNA in situ hybridization protocol; E. Gavis and R. Lehmann for providing the lacZ transcription plasmid and for advice on ovary in situ hybridization; and C. Lee, B. Meyer, S. Misra, K. Mitchell, and D. Rudner for comments on the manuscript. This work was funded by grants from the National Institutes of Health

The publication costs of this article were defrayed in part by payment of page charges. This article must therefore be hereby marked "advertisement" in accordance with 18 USC section 1734 solely to indicate this fact.

\section{References}

Ashburner, M. 1989. Drosophila: A laboratory manual. Cold Spring Harbor Laboratory Press, Cold Spring Harbor, New York.

Ausubel, F.M., R. Brent, R.E. Kingston, D.D. Moore, J.G. Seidman, J.A. Smith, and K. Struhl, eds. 1987. Current protocols in molecular biology. Greene/John Wiley, New York.

Beyer, A.L. and Y.N. Osheim. 1988. Splice site selection, rate of splicing, and alternative splicing on nascent transcripts. Genes \& Dev. 2: 754-765.

Black, D.M., M.S. Jackson, M.G. Kidwell, and G.A. Dover. 1987. $\mathrm{KP}$ elements repress P-induced hybrid dysgenesis in Drosophila melanogaster. EMBO I. 6: 4125-4135.

Carlson, M. and B.C. Laurent. 1994. The SNF/SWI family of global transcriptional activators. Curr. Opin. Cell Biol. 6: 396-402.

Cavener, D.R. 1987. Comparison of the consensus sequence flanking translational start sites in Drosophila and vertebrates. Nucleic Acids Res. 15: 1353-1361.

Coen, D. 1990. P element regulatory products enhance zeste repression of a P[white duplicated] transgene in Drosophila melanogaster. Genetics 126: 949-960.

Ding, D., S.M. Parkhurst, S.R. Halsell, and H.D. Lipshitz. 1993. Dynamic Hsp83 RNA localization during Drosophila oogenesis and embryogenesis. Mol. Cell. Biol. 13: 3773-3781.

Engels, W.R. 1983. The P family of transposable elements in Drosophila. Annu. Rev. Genet. 17: 315-344.

. 1989. P elements in Drosophila melanogaster. In Mobile DNA (ed. D.E. Berg, and M.M. Howe), pp. 437-484. 
American Society for Microbiology, Washington, D.C.

Frankel, A., M. DeCamillis, D. Zink, N. Cheng, H.W. Brock, and R. Paro. 1992. Polycomb and polyhomeotic are constituents of a multimeric protein complex in chromatin of Drosophila melanogaster. EMBO /. 11: 2941-2950.

Friedrich, G. and P. Soriano. 1991. Promoter traps in embryonic stem cells: A genetic screen to identify and mutate developmental genes in mice. Genes \& Dev. 5: 1513-1523.

Gavis, E.R. and R. Lehmann. 1992. Localization of nanos RNA controls embryonic polarity. Cell 71: 301-313.

Gloor, G.B., C.R. Preston, D.M. Johnson-Schlitz, N.A. Nassif, R.W. Phillis, W.K. Benz, H.M. Robertson, and W.R. Engels. 1993. Type I repressors of P element mobility. Genetics 135: 81-95.

Grossniklaus, U., H.J. Bellen, C. Wilson, and W.J. Gehring. 1989. P-element-mediated enhancer detection applied to the study of oogenesis in Drosophila. Development 107: 189-200.

Harding, K., T. Hoey, R. Warrior, and M. Levine. 1989. Autoregulatory and gap gene response elements of the evenskipped promoter of Drosophila. EMBO I. 8: 1205-1212.

Hay, B., L.Y. Jan, and Y.N. Jan. 1988. A protein component of Drosophila polar granules is encoded by vasa and has extensive sequence similarity to ATP-dependent helicases. Cell 55: $577-587$

Herschbach, B.M. and A.D. Johnson. 1993. Transcriptional repression in eukaryotes. Annu. Rev. Cell Biol. 9: 479-509.

Huang, S. and D.L. Spector. 1991. Nascent pre-mRNA transcripts are associated with nuclear regions enriched in splicing factors. Genes \& Dev. 5: 2288-2302.

Jiang, J., D. Kosman, Y.T. Ip, and M. Levine. 1991. The dorsal morphogen gradient regulates the mesoderm determinant twist in early Drosophila embryos. Genes \& Dev. 5: 18811891.

Jiménez-Garcia, L.F. and D.L. Spector. 1993. In vivo evidence that transcription and splicing are coordinated by a recruit ing mechanism. Cell 73: 47-59.

Jones, K.R. and G.M. Rubin. 1990. Molecular analysis of no-on transient $A$, a gene required for normal vision in Drosophila. Neuron 4: 711-723.

Kaufman, P.D. and D.C. Rio. 1991. Drosophila P element transposase acts as a transcriptional repressor in vitro. Proc. Natl. Acad. Sci. 88: 2613-2617.

Laski, F.A. and G.M. Rubin. 1989. Analysis of the cis-acting requirements for germ-line-specific splicing of the P-element ORF2-ORF3 intron. Genes \& Dev. 3: 720-728.

Laski, F.A., D.C. Rio, and G.M. Rubin. 1986. Tissue specificity of Drosophila $\mathrm{P}$ element transposition is regulated at the level of mRNA splicing. Cell 44: 7-19.

Lasko, P.F. and M. Ashburner. 1988. The product of the Drosophila gene vasa is very similar to eukaryotic initiation factor-4A. Nature 355: 611-617.

LeMaire, M.F. and C.S. Thummel. 1990. Splicing precedes polyadenylation during Drosophila E74A transcription. Mol. Cell. Biol. 10: 6059-6063.

Lemaitre, B. and D. Coen. 1991. P regulatory products repress in vivo the $\mathrm{P}$ promoter activity in $\mathrm{P}-\mathrm{lac} \mathrm{Z}$ fusion genes. Proc. Natl. Acad. Sci. 88: 4419-4423.

Lemaitre, B., S. Ronsseray, and D. Coen. 1993. Maternal repression of the $P$ element promoter in the germline of Drosophila melanogaster: A model for the P cytotype. Genetics 135: 149-160.

Mismer, D. and G.M. Rubin. 1987. Analysis of the promoter of the ninaE opsin gene in Drosophila melanogaster. Genetics 116: $565-578$

Misra, S. and D.C. Rio. 1990. Cytotype control of Drosophila P element transposition: The $66 \mathrm{kD}$ protein is a repressor of transposase activity. Cell 62: $269-284$

Misra, S., R.M. Buratowski, T. Ohkawa, and D.C. Rio. 1993. Cytotype control of Drosophila melanogaster P element transposition: Genomic position determines maternal repression. Genetics 135: 785-800.

O'Hare, K. and G.M. Rubin. 1983. Structure of P transposable elements and their sites of insertion and excision in the Drosophila melanogaster genome. Cell 34: 25-35.

O'Hare, K., A. Driver, S. McGrath, and D.M. Johnson-Schlitz. 1992. Distribution and structure of cloned P elements from the Drosophila melanogaster $\mathrm{P}$ strain $\pi_{2}$. Genet. Res. 60: 33-41.

O'Kane, C.J. and W.J. Gehring. 1987. Detection in situ of genomic regulatory elements in Drosophila. Proc. Natl. Acad. Sci. 84: 9123-9127.

Paro, R. 1990. Imprinting a determined state into the chromatin of Drosophila. Trends Genet. 6: 416-421.

Rasmusson, K.E., J.D. Raymond, and M.J. Simmons. 1993. Repression of hybrid dysgenesis in Drosophila melanogaster by individual naturally occurring $\mathrm{P}$ elements. Genetics 133: 605-622.

Rio, D.C. 1991. Regulation of Drosophila P element transposition. Trends Genet. 7: 282-287.

-1993. Splicing of pre-mRNA: Mechanism, regulation and role in development. Curr. Opin. Genet. Dev. 3: 574 584.

Rio, D.C., F.A. Laski, and G.M. Rubin. 1986. Identification and immunochemical analysis of biologically active Drosophila P element transposase. Cell 44: 21-32.

Robertson, H.M. and W.R. Engels. 1989. Modified P elements that mimic the P cytotype in Drosophila melanogaster. Genetics 123: 815-824.

Ronsseray, S., M. Lehmann, and D. Anxolabéhere. 1991. The maternally inherited regulation of P elements in Drosophila melanogaster can be elicted by two $\mathrm{P}$ copies at cytological site 1A on the $X$ chromosome. Genetics 129: 501-512.

Ronsseray, S., B. Lemaitre, and D. Coen. 1993. Maternal inheritance of P cytotype in Drosophila melanogaster: A "pre-P cytotype" is strictly extra-chromosomally transmitted. Mol. \& Gen. Genet. 241: 115-123.

Rubin, G.M. and A.C. Spradling. 1983. Vector for P elementmediated gene transfer in Drosophila. Nucleic Acids Res. 11: 6341-6351.

Sambrook, J., E.F. Fritsch, and T. Maniatis. 1989. Molecular cloning: A laboratory manual. Cold Spring Harbor Laboratory Press, Cold Spring Harbor, New York

Siebel, C.W., R. Kanaar, and D.C. Rio. 1994. Regulation of tissue-specific P-element pre-mRNA splicing requries the RNA-binding protein PSI. Genes \& Dev. 8: 1713-1725.

Siebel, C.W., A. Admon, and D.C. Rio. 1995. Soma-specific expression and cloning of PSI, a negative regulator of $\mathrm{P}$ element pre-mRNA splicing. Genes \& Dev. 9: 269-283.

Spradling, A.C. 1986. P element-mediated transformation. In Drosophila: A practical approach (ed. D. Roberts), pp. 175197. IRL Press, Oxford, UK.

Spradling, A.C. and G.M. Rubin. 1982. Transposition of cloned P elements into Drosophila germ line chromosomes. Science 218: $341-347$.

Tiian, R. 1981. T antigen binding and the control of SV40 gene expression. Cell 26: 1-2.

Winston, F. and M. Carlson. 1992. Yeast SNF/SWI transcriptional activators and the SPT/SIN chromatin connection. Trends Genet. 8: 387-391.

Xing, Y. and J.B. Lawrence. 1993. Nuclear RNA tracks: Structural basis for transcription and splicing? Trends Cell Biol. 3: $346-353$. 


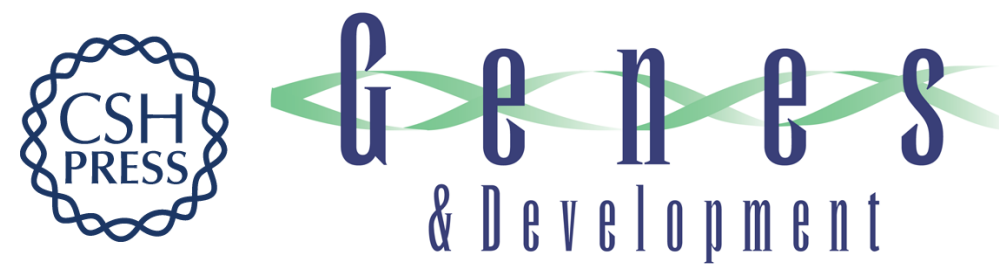

\section{P-element repressor autoregulation involves germ-line transcriptional repression and reduction of third intron splicing.}

S E Roche, M Schiff and D C Rio

Genes Dev. 1995, 9:

Access the most recent version at doi:10.1101/gad.9.10.1278

References This article cites 47 articles, 22 of which can be accessed free at:

http://genesdev.cshlp.org/content/9/10/1278.full.html\#ref-list-1

License

Email Alerting

Service

Receive free email alerts when new articles cite this article - sign up in the box at the top right corner of the article or click here.

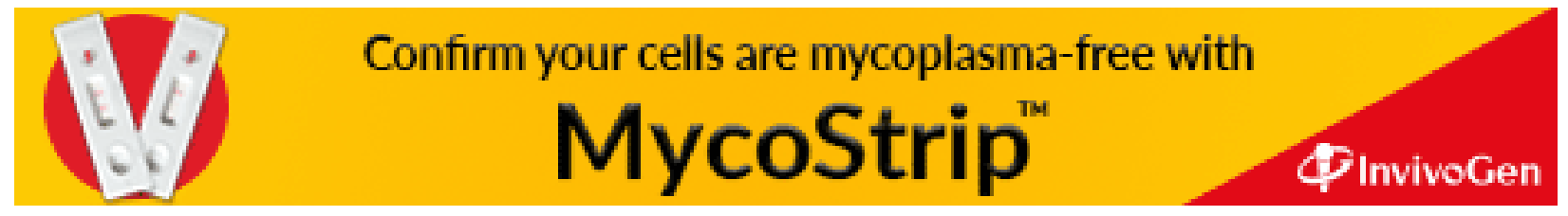

